\title{
Calcified intracranial tuberculomas as sequelae of pediatric neurotuberculosis
}

Tuberculomas calcificados intracranianos como sequela de neurotuberculose pediátrica Carolina de Medeiros RIMKUS', Thiago Augusto Vasconcelos MIRANDA', Leandro Tavares LUCATO'

A 29-year-old woman with a history of neurotuberculosis at the age of 18 months presented with seizures, abnormal gait, and fluctuations of consciousness level, recovering after anti-tuberculosis treatment. She remained asymptomatic for the next years, except for moderate cognitive impairment. Years later, a brain magnetic resonance imaging (MRI) scan (Figure 1) revealed calcified lobulated masses in the brain parenchyma and basal cisterns.

Intracranial tuberculomas occur in 5-24\% of pediatric neurotuberculosis ${ }^{1}$ and can be secondary to pial vessel inflammation, perivascular abscesses, or septic emboli². Medical history and the characterization of non-enhancing, diffusely calcified brain masses are important clues for diagnosing residual granulomas.

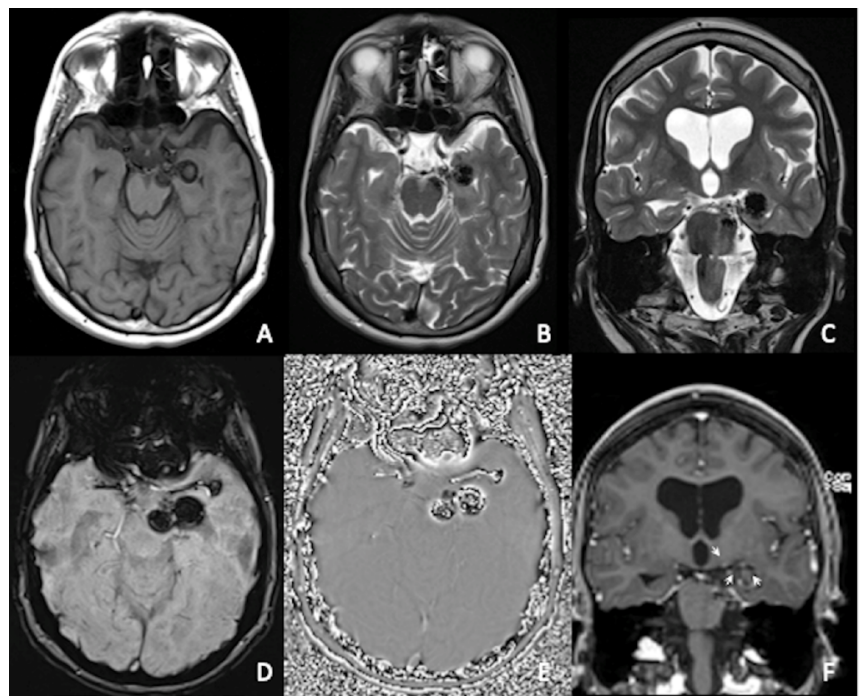

Figure 1. Magnetic resonance imaging shows multiple lobulated masses with low signal in T1-weighted (A) and T2-weighted (B and $\mathrm{C}$ images in the brain parenchyma and basal cisterns, with low signal in susceptibility-weighted imaging (SWI) (D) and phase images (E), compatible with calcifications. Lesions are non-enhancing in post-gadolinium images (F), except for a few peripheral enhancing foci (arrows), corresponding to small vessels.

1. Chiang SS, Khan FA, Milstein MB, Tolman AW, Benedetti A, Starke JR, et al. Treatment outcomes of childhood tuberculous meningitis: a systematic review and meta-analysis. Lancet Infect Dis. 2014 Oct;14(10):947-57. https://doi.org/10.1016/S1473-3099(14)70852-7
2. Rock RB, Olin M, Baker CA, Molitor TW, Peterson PK. Central nervous system tuberculosis: pathogenesis and clinical aspects. Clin Microbiol Rev. 2008 Apr;21(2):243-61. https://doi.org/10.1128/ CMR.00042-07

\footnotetext{
${ }^{1}$ Universidade de São Paulo, Faculdade de Medicina, Departamento de Radiologia e Oncologia, São Paulo SP, Brazil.

Carolina de Medeiros RIMKUS (D) https://orcid.org/0000-0002-3866-1299; Thiago Augusto Vasconcelos MIRANDA (iD https://orcid.org/0000-0002-8144-0758; Leandro Tavares LUCATO (iD) https://orcid.org/0000-0001-9181-5245
}

Correspondence: Carolina de Medeiros Rimkus; E-mail: carolina.rimkus@hc.fm.usp.br

Conflict of interest: There is no conflict of interest to declare.

Authors' contributions: CMR: study conceptual design, imaging analysis, writing and review of the manuscript. TAV: imaging and clinical data acquisition, review of the manuscript. LTL: imaging analysis, writing and review of the manuscript.

Received on June 8, 2020; Received in its final form on July 19, 2020; Accepted on July 25, 2020. 